\title{
EFFICIENCY COMPARISON AND EFFICIENCY DEVELOPMENT OF THE METALLURGICAL INDUSTRY IN THE EU: PARAMETRIC AND NON-PARAMETRIC APPROACHES
}

\author{
Michaela Staňková ${ }^{1}$ \\ ${ }^{1}$ Department of Statistics and Operation Analysis, Faculty of Business and Economics, Mendel University in Brno, \\ Zemědělská 1, 61300 Brno, Czech Republic
}

Link to this article: https://doi.org/10.11118/actaun202068040765

Received: 28. 6. 2020, Accepted: 13. 8. 2020

To cite this article: STAŇKOVÁ MICHAELA. 2020. Efficiency Comparison and Efficiency Development of the Metallurgical Industry in the EU: Parametric and Non-parametric Approaches. Acta Universitatis Agriculturae et Silviculturae Mendelianae Brunensis, 68(4): 765-774.

\begin{abstract}
This article deals with the development of technical (production) efficiency in the metallurgical industry in EU countries with an emphasis on the situation in the Czech Republic. The efficiency of individual countries was estimated for the period from 1995 to 2015. The parametric stochastic frontier analysis method with different settings was chosen to estimate efficiency and the results were verified using a competitive non-parametric data envelopment analysis method. It was found that during the period under review, there was an average increase in efficiency in the metallurgical industry. The largest increase in efficiency (confirmed by all types of models) was observed in the Czech Republic. A visible positive efficiency shift was also recorded in Spain and Greece. Surprisingly, there has been a decline in efficiency in Sweden and Italy.
\end{abstract}

Keywords: data envelopment analysis, efficiency, Malmquist index, metallurgical industry, panel data, stochastic frontier analysis

\section{INTRODUCTION}

Efficiency evaluation (regardless of the chosen sector) is a constantly discussed issue, see Staňková and Hampel (2018) or Staňková and Hampel (2019). This evaluation is based on the idea of dividing units into efficient and inefficient ones. Efficiency is meant here in the production sense. An efficient unit cannot produce more of one good unless the production of other goods is restricted. Both parametric and non-parametric methods are used in the field of efficiency evaluation. Li, Chiu and Lin (2019), Hosseinzadeh et al. (2016) and Yang et al. (2014) used a non-parametric approach and evaluated efficiency within the mining and steel industries using the data envelopment analysis (DEA) method. The DEA method is based on linear programming and is not burdened by assumptions about the shape of the production frontier or the probability distribution. However, it is a deterministic method and so it is not possible to distinguish noise from inefficiency via the DEA method. For this reason, Charoenrat and Harvie (2014) preferred to apply the parametric stochastic frontier analysis (SFA) method to evaluate the efficiency of Thai manufacturing companies. The application of the SFA method allowed them to distinguish random errors from inefficiency and also their hypotheses could be tested with statistical rigour. Other studies using the SFA method can be named from the mining industry; for example Wang, Wan and Yang (2019) and Wu et al. (2019). The parametric approach is criticized mainly for the assumption that the production function has the same functional form for all the units in the dataset; the fact that econometric estimation of efficiency can 
produce inconsistent parameter estimates. According to Silva et al. (2016), it is appropriate to compare the results with another approach, regardless of the chosen method.

The metallurgical industry has a long history in the Czech Republic and the whole of Europe. Changes in the metallurgical industry affect other sectors such as for example the engineering industry. Metals and metal processing technology have their own civilizational periods, such as the Bronze and Iron Ages. According to a report by the European Commission (2004) this sector has undergone considerable development in recent years. Activities related to the metallurgical industry represent almost half of the total manufacturing value and one tenth of the total gross domestic product of the European Union. These changes have been made possible mainly by the development of new technologies, including nanotechnologies, raw material and waste minimization and advanced energy conservation. According to the European Commission (2004), processes in this sector are constantly becoming more efficient and proficient, limiting the risk of pollution.

The main aim of this article is to evaluate the development of the efficiency of the metallurgical industry in EU from 1995 to 2015. A partial goal is to evaluate the situation of the Czech Republic in comparison with other EU countries. For these purposes, the SFA method has been chosen, which, as already mentioned, allows one to distinguish noise and inefficiencies. Given the size of the database, it is necessary to use SFA panel models. To ensure robust results, estimates of efficiency will be made using various SFA models with different settings. With regard to the recommendations of Silva et al. (2016), the results of SFA panel models will be contrasted with the results of the DEA method.

\section{MATERIALS AND METHODS}

Efficiency estimates will be based on annual data from the EU KLEMS database for the 'Basic metals and fabricated metal products, except machinery and equipment' sector (NACE codes 24 and 25 taken together). The calculations will be based on data from 1995 to 2015. The parametric models will be based on the Cobb-Douglas two-factor production function like in Staňková and Hampel (2019). Due to data availability in the EU KLEMS database, it is possible to consider two variables as the output variable: gross value added (VA) and gross output (GO); both at current basic prices in millions of national currencies. The number of employees (EMPE) in thousands and nominal gross fixed capital formation (GFCF) in millions of national currencies will represent the labour and capital factor. As the values in the EU KLEMS database are given in national currency, the data obtained were converted into euros using annual exchange rates.

Unfortunately, Belgium, Croatia, Ireland and Cyprus did not have any values available at all within the NACE C sector. Bulgaria, Estonia, Lithuania, Latvia, Luxembourg, Hungary, Malta, Poland, Portugal, Romania and Slovenia had data available only for the whole of sector $\mathrm{C}$ and not for the observed metallurgical sector. Slovakia also had to be removed from the dataset, as it had data available only after 2004. The Netherlands only had values for GFCF available from 1999, but as there are only four missing observations, the Netherlands has been kept in the dataset. In total, it was possible to make estimates for 12 EU countries. The average annual values of all variables in individual years (number of employees in thousands, other variables in billions of EUR) are in Fig. 1.
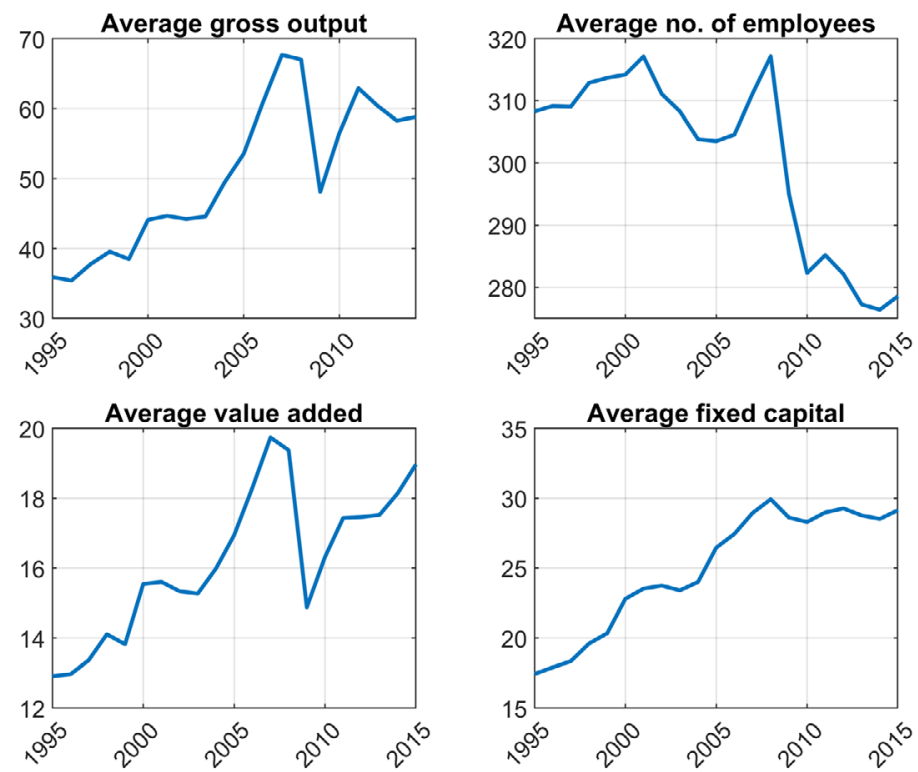

1: Average values of variables used for evaluation in individual years (number of employees in thousands, other variables in billions of EUR) 
The number of employees in this sector has decreased on average over the years. On the other hand, there was growth in the variables representing the output; i.e. average GO and average VA. Both output variables in Fig. 1 have a similar trend. The correlation between the average values of GO and VA is 0.9654 in the case of Pearson's correlation coefficient. In the case of the variable fixed capital (GFCF), there was an increase from 1995 to 2015 on average. However, for example, during the global crisis (2009 and 2010), the GFCF values fell.

\section{Models Used for Efficiency Evaluation}

Due to the nature of the data, SFA panel models will be used. Given the length of the period chosen, it can be assumed that the efficiency will change over time, and therefore only those types of SFA models were chosen that allow this change in efficiency to be captured. Both true SFA panel models from Greene (2005) will be applied. Both the true SFA model with fixed effects (TFE), and with random effects (TFE) will be considered. As a third model, another representative of time-variant models according to Battese and Coelli (1995) will be used. In this model, the change in efficiency is calculated based on the subsequent time-decomposition.
Therefore, these models are often referred to as time-decay (TD) models.

The TD model by Battese and Coelli (1995) assumes a truncated-normal distribution of inefficiency. The models by Greene (2005) allow for wider settings, so the three most frequently mentioned probability distributions will be considered. Namely, these are the exponential, half-normal and truncated-normal distributions of inefficiency. The SFA panel data models will be estimated assuming no change in the efficiency frontier, as well as with linear and exponential growth. Another change in the efficiency evaluation will concern the selected efficiency estimator. Two estimators will be used in this article. Both estimates will be based on a conditional mean of the distribution. The $\mathrm{BC}$ estimator (Battese and Coelli, 1988) directly estimates efficiency while the JLMS estimates (Jondrow et al., 1982) inefficiency, which then needs to be converted to efficiency. A detailed description of these procedures can be found in Kumbhakar, Wang and Horncastle (2015). Since two efficiency estimators will be used, there will be a total of 84 efficiency estimates based on 42 SFA panel data models. A more detailed overview of the estimated models with respect to individual settings is given in Tab. I.

I: Overview of used SFA panel models due to different settings. Model: time-decay (TD), true fixed effects (TFE), true random effects (TRE). Output: value added (VA), gross output (GO). Distribution: exponential (EX), half-normal (HN), truncated-normal (TN). Frontier shift: none (N), exponential (E), linear (L). M01 to M42 is the model label.

\begin{tabular}{|c|c|c|c|c|c|c|c|c|c|}
\hline Model & Output & Shift & Distribution & Label & Model & Output & Shift & Distribution & Label \\
\hline TD & VA & $\mathrm{N}$ & $\mathrm{TN}$ & M01 & TRE & VA & E & $\mathrm{HN}$ & M22 \\
\hline TD & VA & E & $\mathrm{TN}$ & M02 & TRE & VA & $\mathrm{L}$ & $\mathrm{HN}$ & M23 \\
\hline TD & VA & $\mathrm{L}$ & $\mathrm{TN}$ & M03 & TRE & VA & E & $\mathrm{TN}$ & M24 \\
\hline TD & GO & $\mathrm{N}$ & $\mathrm{TN}$ & M04 & TRE & VA & $\mathrm{L}$ & $\mathrm{TN}$ & M25 \\
\hline TFE & VA & $\mathrm{N}$ & $\mathrm{HN}$ & M05 & TRE & VA & $\mathrm{N}$ & EX & M26 \\
\hline TFE & VA & E & $\mathrm{HN}$ & M06 & TRE & VA & $E$ & EX & M27 \\
\hline TFE & VA & $\mathrm{L}$ & $\mathrm{HN}$ & M07 & TRE & VA & $\mathrm{L}$ & EX & M28 \\
\hline TFE & VA & $\mathrm{N}$ & $\mathrm{TN}$ & M08 & TRE & GO & $\mathrm{N}$ & $\mathrm{HN}$ & M29 \\
\hline TFE & VA & E & $\mathrm{TN}$ & M09 & TRE & GO & E & $\mathrm{HN}$ & M30 \\
\hline TFE & VA & $\mathrm{L}$ & $\mathrm{TN}$ & M10 & TRE & GO & $\mathrm{L}$ & $\mathrm{HN}$ & M31 \\
\hline TFE & VA & $\mathrm{N}$ & EX & M11 & TRE & GO & $\mathrm{N}$ & EX & M32 \\
\hline TFE & VA & E & EX & M12 & $\mathrm{TD}$ & GO & E & $\mathrm{TN}$ & M33 \\
\hline TFE & VA & $\mathrm{L}$ & EX & M13 & TD & GO & $\mathrm{L}$ & $\mathrm{TN}$ & M34 \\
\hline TFE & GO & $\mathrm{N}$ & HN & M14 & TFE & GO & E & EX & M35 \\
\hline TFE & GO & $E$ & HN & M15 & TFE & GO & $\mathrm{L}$ & EX & M36 \\
\hline TFE & GO & $\mathrm{L}$ & $\mathrm{HN}$ & M16 & TRE & VA & $\mathrm{N}$ & $\mathrm{TN}$ & M37 \\
\hline TFE & GO & $\mathrm{N}$ & $\mathrm{TN}$ & M17 & TRE & GO & $\mathrm{N}$ & $\mathrm{TN}$ & M38 \\
\hline TFE & GO & E & $\mathrm{TN}$ & M18 & TRE & GO & $E$ & $\mathrm{TN}$ & M39 \\
\hline TFE & GO & $\mathrm{L}$ & $\mathrm{TN}$ & M19 & TRE & GO & $\mathrm{L}$ & $\mathrm{TN}$ & M40 \\
\hline TFE & GO & $\mathrm{N}$ & EX & M20 & TRE & GO & E & EX & M41 \\
\hline TRE & VA & $\mathrm{N}$ & HN & M21 & TRE & GO & $\mathrm{L}$ & EX & M42 \\
\hline
\end{tabular}


In cases where the development of efficiency in individual SFA panel models is significantly different, it is possible to compare the development of efficiency within the non-parametric approach. Within the DEA method, it is then possible to use the Malmquist index (MI), which allows detection of a change in technical efficiency and a change within the production possibility frontier. Details on the calculation of MI as well as its decomposition into the two components can be found in Thanassoulis (2013). If the resulting value of MI (and thus its subcomponents) is equal to 1 , this speaks of the stability of the results over time. Index values greater than 1 indicate improvement; values less than 1 indicate a deterioration in the situation.

The MI can be constructed via the DEA method using various settings. Even within the nonparametric approach, several different models will be used, the results of which will be averaged in order to avoid the influence of a specific setting of the DEA model on the calculation of technical efficiency. The 10 most frequently used variants of DEA models will be constructed. Since the CobbDouglas production function allows constant and variable returns to scale, DEA models will also be constructed in a variant of constant and variable returns to scale. Both radial (i.e. CCR and BCC) models and SBM (slack based measure) models will be taken into account. Another assumption that needs to be introduced within the DEA method concerns the orientation of the model. It is possible to work with input-oriented as well as outputoriented models. In addition, SBM models make it possible to combine both of these variants and become so-called non-oriented models. A detailed description of all these DEA models can be found in Cooper, Seiford and Tone (2007). An overview of DEA models used to calculate MI including their specific settings can be found in Tab. II.

All the procedures described will be performed using the Stata 15.1 computer system (functions developed according to Belotti et al. (2013)), the DEA SolverPro program (version 15) and the MATLAB 2019a computer system (Statistics and Machine Learning Toolbox).

\section{RESULTS}

Of the originally planned 42 SFA panel models (i.e. 84 efficiency estimates), only models M01 to M32 (i.e. 64 efficiency estimates) could be estimated. In nine out of ten cases where it was not possible to estimate the parameters of the model, the variable GO was used. It can be stated that within the models M33 to M42 only models with exponential or truncated-normal distribution appear. In the case of TFE and TD models, where it was not possible to make an estimate, these were always models with the assumption of some shift of the efficiency frontier. The most common problems with model estimation were observed in the group of TRE models (a total of six out of 10 cases). Models M37 to M42 differ in the type of distribution, in the assumption about the frontier shift and in the output variable used, so it is not possible to determine only one problem area. For models M01 to M32, estimates were obtained with all statistically significant parameters. However, some differences can be seen between these models.

In the case of TFE models, these have always been models that can be characterized by increasing returns to scale. In the case of TFE models, it can also be stated that in all cases there were also increasing returns to scale, but the estimated values of the parameters were lower compared to TFE models. The last group of the model (TD models) can be characterized by constant returns to scale.

The differences between the individual types of models were also not found in the value of the estimated efficiency itself. Furthermore, it was found that the estimated efficiency is influenced by the chosen efficiency estimator. The following Tab. III shows, for illustration, the average efficiency values for the entire period for each country with respect to a given model type and efficiency estimator type. It was found that in the case of TD and TFE models, higher efficiency values were achieved on average through the BC efficiency estimator. However, the differences in efficiency were a maximum of 0.30 for TD models and 0.10 percentage points for TFE models. In the case of TRE models, the average efficiency values differs the most. The largest difference (over 31 percentage points) was measured in the case of the Czech Republic. However, in the case of TRE models, the statement that the BC estimate would generally give a higher average efficiency score cannot be applied.

TD models generally led to significantly lower values for the average efficiency of a given country.

II: An overview of DEA models used to calculate MI with respect to a given setting

\begin{tabular}{lccccc}
\hline \multicolumn{1}{c}{ Model } & Returns to scale & Orientation & Model & Returns to scale & Orientation \\
\hline Radial (CCR) & Constant & Input & SBM & Variable & Non-oriented \\
Radial (CCR) & Constant & Output & SBM & Constant & Input \\
Radial (BCC) & Variable & Input & SBM & Constant & Output \\
Radial (BCC) & Variable & Output & SBM & Variable & Input \\
SBM & Constant & Non-oriented & SBM & Variable & Output \\
\hline
\end{tabular}


III: Average efficiency of countries (in \%) according to individual types of SFA models and efficiency estimator

\begin{tabular}{|c|c|c|c|c|c|c|c|c|c|}
\hline \multirow{2}{*}{ Country } & \multicolumn{3}{|c|}{ TD models } & \multicolumn{3}{|c|}{ TFE models } & \multicolumn{3}{|c|}{ TRE models } \\
\hline & All & JLSM & $\mathrm{BC}$ & All & JLSM & $\mathrm{BC}$ & All & JLSM & $\mathrm{BC}$ \\
\hline Austria & 81.56 & 81.44 & 81.68 & 91.83 & 91.78 & 91.87 & 93.90 & 93.64 & 94.16 \\
\hline Czech Rep. & 40.03 & 39.91 & 40.14 & 88.40 & 88.35 & 88.44 & 74.11 & 89.74 & 58.48 \\
\hline Denmark & 82.25 & 82.13 & 82.38 & 91.71 & 91.67 & 91.75 & 94.25 & 93.02 & 95.49 \\
\hline Finland & 81.27 & 81.18 & 81.36 & 90.00 & 89.96 & 90.05 & 92.39 & 90.71 & 94.08 \\
\hline France & 84.33 & 84.24 & 84.42 & 92.08 & 92.04 & 92.12 & 91.43 & 93.89 & 88.97 \\
\hline Germany & 89.78 & 89.71 & 89.85 & 90.62 & 90.57 & 90.67 & 90.73 & 92.63 & 88.83 \\
\hline Greece & 79.39 & 79.30 & 79.48 & 86.63 & 86.58 & 86.68 & 89.22 & 85.18 & 93.26 \\
\hline Italy & 75.80 & 75.68 & 75.93 & 91.36 & 91.32 & 91.41 & 87.16 & 93.27 & 81.05 \\
\hline Netherlands & 81.52 & 81.40 & 81.64 & 91.04 & 91.00 & 91.09 & 92.98 & 93.10 & 92.85 \\
\hline Spain & 66.57 & 66.44 & 66.70 & 91.78 & 91.74 & 91.83 & 85.08 & 93.56 & 76.60 \\
\hline Sweden & 85.34 & 85.26 & 85.42 & 90.37 & 90.32 & 90.41 & 93.13 & 92.16 & 94.10 \\
\hline UK & 67.17 & 67.02 & 67.31 & 90.21 & 90.17 & 90.26 & 84.35 & 91.92 & 76.77 \\
\hline Average & 76.25 & 76.14 & 76.36 & 90.50 & 90.46 & 90.55 & 89.06 & 91.90 & 86.22 \\
\hline
\end{tabular}

The biggest differences between the methods are evident in the Czech Republic, which in the case of the TFE model achieved a 48.37 percentage point higher efficiency score than in the TD model; in the case of the TRE models, the difference is 34.08 percentage points. The differences between the individual types of models and, in the case of TRE models, also the influence of the efficiency estimate itself, were reflected not only in the level of efficiency itself, but also in the final rank, see Tab. IV that shows the average rank of each country.

Based on the information from Tab. III and IV, it can be stated that companies in the Czech Republic in the metallurgical industry are on average less efficient than their competitors from other countries. In particular, TD models point to the strong inefficiency of Czech companies. However, if we look at the change in efficiency - comparison in 2015 and 1995 (in the case of the Netherlands, this is a change in 2015 and 1999), it is the Czech Republic that has the strongest improvement, see Tab. V. All SFA models agree that during the period under review, the efficiency of companies in the Czech metallurgical industry increased. The exact value of this increase then depends on the specific setting of the SFA model. However, the differences between the individual SFA models are a maximum of two percentage points. If the results of individual

IV: Average rank of countries based on average efficiency according to the individual types of SFA models and efficiency estimator

\begin{tabular}{lcccccccccc}
\hline \multirow{2}{*}{ Country } & \multicolumn{3}{c}{ TD models } & \multicolumn{3}{c}{ TFE models } & \multicolumn{3}{c}{ TRE models } \\
\cline { 2 - 11 } & All & JLSM & BC & All & JLSM & BC & All & JLSM & BC \\
\hline Austria & 5 & 5 & 5 & 2 & 2 & 2 & 2 & 2 & 2 \\
Czech Rep. & 12 & 12 & 12 & 11 & 11 & 11 & 12 & 11 & 12 \\
Denmark & 4 & 4 & 4 & 4 & 4 & 4 & 1 & 6 & 1 \\
Finland & 7 & 7 & 7 & 10 & 10 & 10 & 5 & 10 & 4 \\
France & 3 & 3 & 3 & 1 & 1 & 1 & 6 & 1 & 7 \\
Germany & 1 & 1 & 1 & 7 & 7 & 7 & 7 & 7 & 8 \\
Greece & 8 & 8 & 8 & 12 & 12 & 12 & 8 & 12 & 5 \\
Italy & 9 & 9 & 9 & 5 & 5 & 5 & 9 & 4 & 9 \\
Netherlands & 6 & 6 & 6 & 6 & 6 & 6 & 4 & 5 & 6 \\
Spain & 11 & 11 & 11 & 3 & 3 & 3 & 10 & 3 & 11 \\
Sweden & 2 & 2 & 2 & 8 & 8 & 8 & 3 & 8 & 3 \\
UK & 10 & 10 & 10 & 9 & 9 & 9 & 11 & 9 & 10 \\
\hline
\end{tabular}


V: Comparison of efficiency in 2015 and 1995 (in the case of the Netherlands, the change is in 2015 to 1999) in \%

\begin{tabular}{|c|c|c|c|c|c|c|c|c|c|}
\hline \multirow{2}{*}{ Country } & \multicolumn{3}{|c|}{ TD models } & \multicolumn{3}{|c|}{ TFE models } & \multicolumn{3}{|c|}{ TRE models } \\
\hline & All & JLSM & $\mathrm{BC}$ & All & JLSM & $\mathrm{BC}$ & All & JLSM & $\mathrm{BC}$ \\
\hline Austria & 1.20 & 1.22 & 1.19 & -1.84 & -1.86 & -1.83 & -0.25 & -0.20 & -0.29 \\
\hline Czech Rep. & 14.55 & 14.52 & 14.58 & 12.57 & 12.62 & 12.53 & 13.77 & 15.24 & 12.30 \\
\hline Denmark & 0.34 & 0.33 & 0.34 & 1.24 & 1.25 & 1.22 & 0.67 & 0.86 & 0.47 \\
\hline Finland & -7.36 & -7.39 & -7.34 & -5.24 & -5.28 & -5.20 & -4.33 & -5.59 & -3.08 \\
\hline France & -3.55 & -3.57 & -3.52 & -0.26 & -0.26 & -0.25 & -1.44 & -1.21 & -1.67 \\
\hline Germany & 9.77 & 9.82 & 9.71 & 6.24 & 6.29 & 6.20 & 5.80 & 5.50 & 6.09 \\
\hline Greece & 13.10 & 13.13 & 13.06 & 4.91 & 4.94 & 4.88 & 5.21 & 7.52 & 2.91 \\
\hline Italy & -10.18 & -10.21 & -10.14 & -4.18 & -4.21 & -4.14 & -6.65 & -4.87 & -8.43 \\
\hline Netherlands & 7.59 & 7.65 & 7.53 & 5.03 & 5.07 & 4.99 & 3.55 & 4.07 & 3.03 \\
\hline Spain & 12.81 & 12.84 & 12.78 & 4.60 & 4.64 & 4.57 & 8.27 & 6.09 & 10.45 \\
\hline Sweden & -8.73 & -8.79 & -8.67 & -3.95 & -3.98 & -3.91 & -3.34 & -4.08 & -2.59 \\
\hline UK & -4.98 & -4.99 & -4.98 & 0.10 & 0.10 & 0.10 & -1.07 & -0.49 & -1.66 \\
\hline Average & 2.05 & 2.05 & 2.05 & 1.60 & 1.61 & 1.60 & 1.68 & 1.90 & 1.46 \\
\hline
\end{tabular}

models were averaged into a single SFA model, then in the case of the Czech Republic this is an increase in efficiency of 13.27 percentage points. The overall increase in efficiency can also be found in other countries such as Germany and Spain. However, most countries, such as Denmark and Austria, do not have a significant overall change in efficiency in 1995 and 2015. If the results of individual countries were averaged, we can speak (especially thanks to the values of the Czech Republic, Spain and Greece) of an overall increase (about two percentage points) in efficiency in the metallurgical industry.

However, this one-digit characteristic in Tab. $\mathrm{V}$ does not truly reflect the development of efficiency over time. For this purpose, the efficiency of companies in the Czech Republic was plotted together with three other countries which in Tab. IV appeared in first place in the derived order of efficiency - Germany according to TD models, France according to TFE models and Denmark according to TRE models. At the same time, these are countries that represent two groups of countries. The Czech Republic and Germany represent countries that have undergone a strong development in efficiency. Denmark and France, on the other hand, represent countries that are characterized by only minor fluctuations in terms of efficiency. In Fig. 2, for greater clarity, only the average values of technical efficiency (in \%) for TD (blue), TFE (orange) and TRE (red) models for the whole monitored period for the Czech Republic, Germany, France and Denmark were plotted. However, it was Denmark that compared to other countries in Fig. 2 showed the most stable development. It can therefore be stated that MI confirms the reliability of the SFA models.

It was found that the Czech Republic started at lower values of efficiency in comparison with the other depicted countries. It can be assumed that this poor starting position was the result of operations under communism. Unfortunately, it was not possible to obtain data that would confirm the stagnation of the economy in the 1980s and 1990s. Data were also not available for other former socialist countries such as Poland or Slovakia, which often now serve as a comparative guide. Within the Czech Republic (similarly to the case of Germany), an increase in efficiency can be seen over time. This growth can be explained mainly by the privatization of the sector (the so-called largescale privatization). This inflow of capital enabled the purchase of new equipment and thus helped to increase technical efficiency in the Czech Republic. Efficiency developments in countries such as France and Denmark are quite different. Although there are obvious fluctuations (e.g. the largest decline in 2009 corresponds to the global economic crisis), the values for technical efficiency in 2015 are very similar to those in 1995.

According to Knížek (2018), the development of the entire Czech metallurgical industry can be illustrated by the development of the Vítkovice ironworks. This statement is confirmed by the estimated SFA models. After 1996 there was a slight decrease in efficiency and in 1999 there is a clear drop in efficiency. This development fully corresponds to the situation at the Vitkovice ironworks at the end of the century, because in 1996 the government decided to stop the production of pig iron, which was actually abolished at the end of 1998. On the contrary, a greater increase in technical efficiency (especially with the TD model) is then evident in 2004. This increase can also be explained by developments at the Vítkovice Ironworks. In 2003, the government decided to 

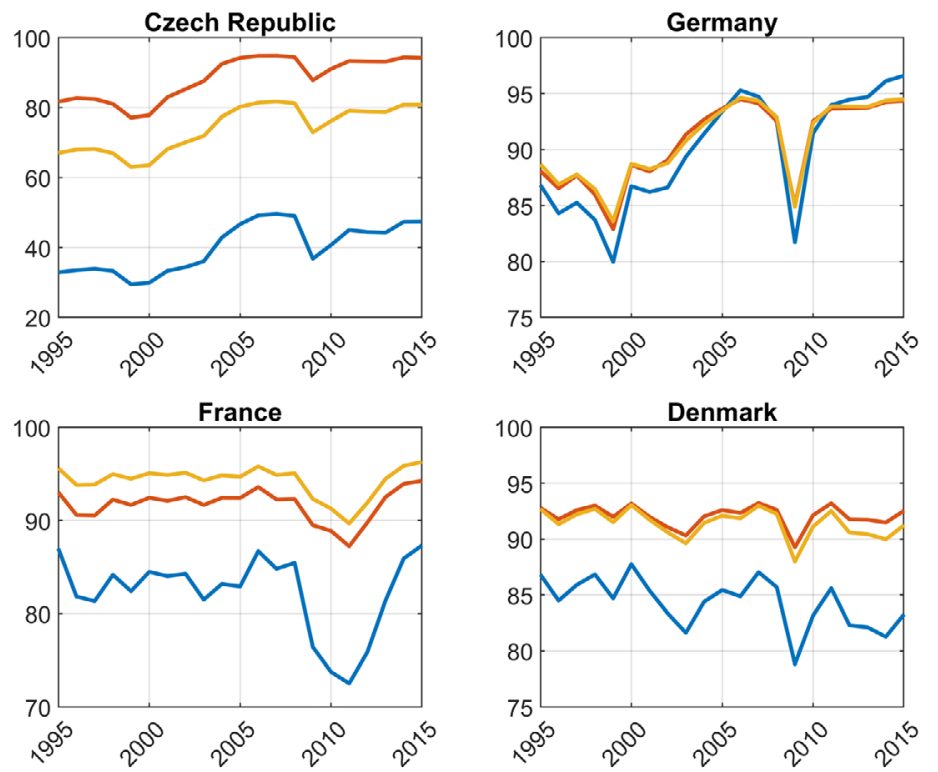

2: Development of efficiency (in \%) in the Czech Republic, Germany, France and Denmark based on TD (blue), TFE (orange) and TRE (red) models in 1995-2015
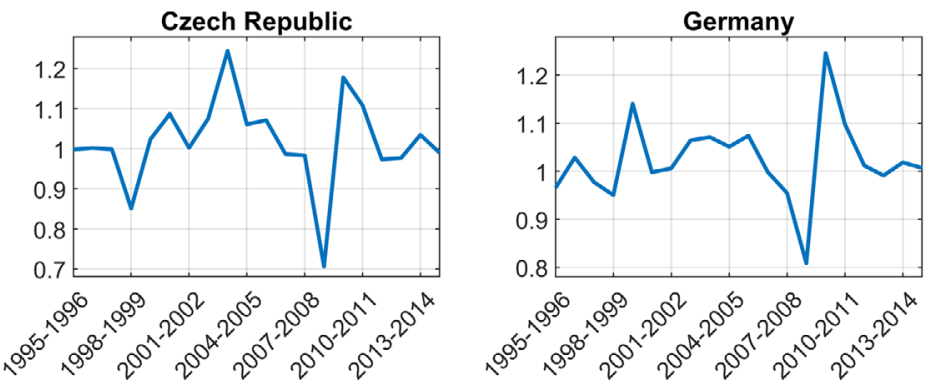

France
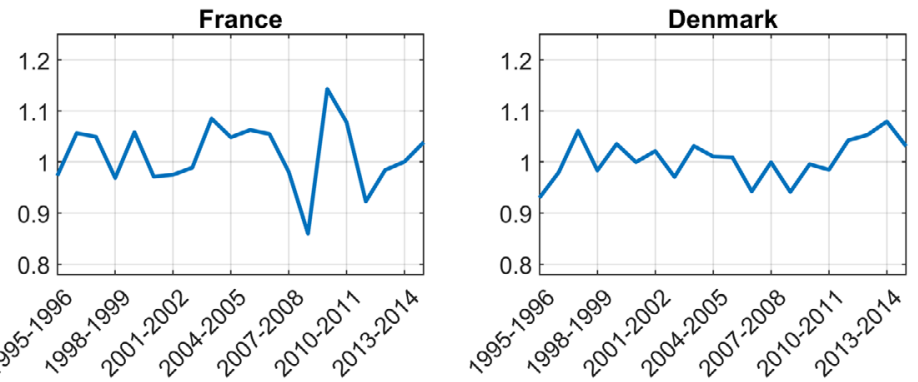

3: Average year-on-year change in the overall situation in the Czech Republic according to MI values in 1995-2015

transfer Vítkovice (as well as other entities) into private ownership. Subsequent efficiency growth in the entire metallurgical industry was then thwarted by the crisis in 2009. Later, the efficiency development points to stagnation (in the case of the TD model even a decrease of 1\%) from 2012 to 2013. Even for this period, a parallel can be found with the overall development of the economy. This is precisely 2012, when a decline in GDP was observed for the first time since the crisis in 2009.

The credibility of efficiency development via SFA models can also be verified using a non-parametric approach. MI values can be used for these purposes. Fig. 3 represents the average MI values for the same countries as in the previous Fig. 2. These average MI values were obtained from all the DEA models in Tab. II. It can be stated that the development within MI corresponds to the findings within SFA models. In the case of the Czech Republic and Germany, despite slight fluctuations, an increase in efficiency can be observed at the beginning of the period under review. Furthermore, according to the MI result, a significant decline corresponding to the world crisis already mentioned is visible in these two 

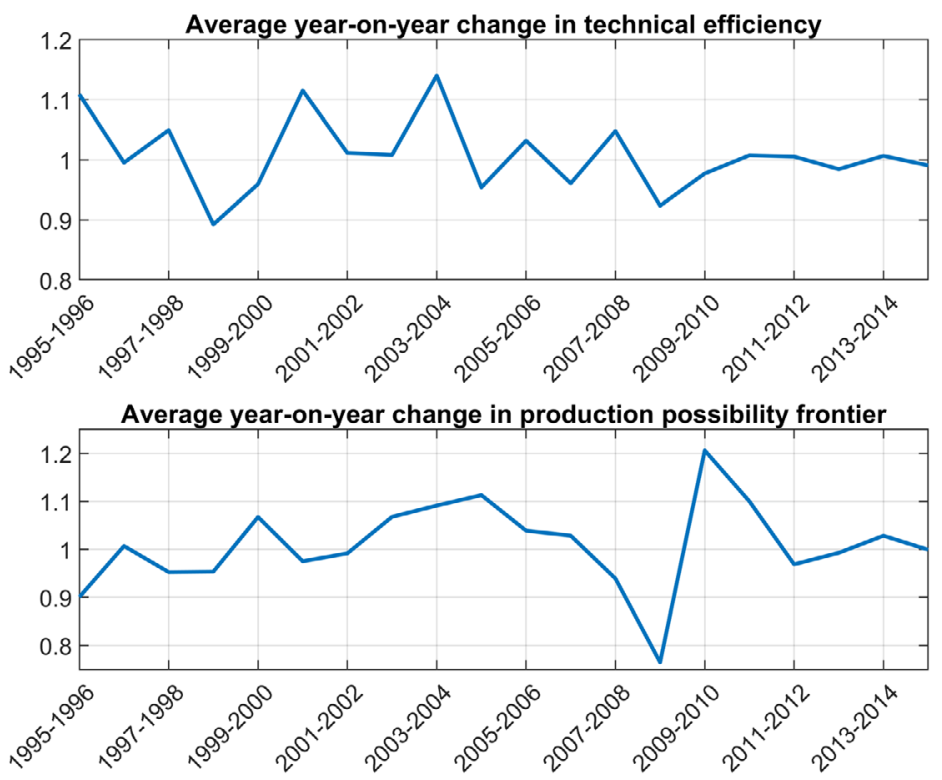

4: Average year-on-year change in technical efficiency and production possibility frontier in the Czech Republic in the years 1995-2015

countries. This crisis is also visible in France's results. In the case of Denmark, there was only a slight decrease in MI values for the period around 2009.

In the case of MI, it is necessary to realize that it evaluates the overall situation of the unit. This is a multiplicative effect of a change in technical efficiency and a change in production frontier. If there is a slight decrease in technical efficiency but there is no stronger drop in the limit of production possibility frontier, then the total MI will be close to 1 - which has just happened in the case of Denmark. With regard to the scope of analysis, a detailed view of the changes within the subcomponents of the MI will be demonstrated only using the example of the Czech Republic, which according to SFA models is the least efficient. Fig. 4 presents the average values for all calculated DEA models according to Tab. II, or rather all MI and its components corresponding in their settings to these DEA models. In Fig. 4, the two components of MI are presented separately, i.e. change in technical efficiency and change within the production possibility frontier. Similarly to MI, values greater than one mean an improvement (an increase in average technical efficiency or production frontier), values less than one, a deterioration (a decrease in average technical efficiency or production frontier), a value equal to one means stagnation.

Despite smaller fluctuations, the values of the change in the production possibility frontier show initial growth, which was then strongly affected by the global economic crisis already mentioned - the biggest decline is evident between 2008 and 2009 . The economic slowdown in 2012 and following years is also evident in Fig. 4. As part of monitoring the change in technical efficiency only, a strong decline is evident at the end of the last century, which corresponds to the values from the SFA models. The increase in efficiency at the beginning of the $21^{\text {st }}$ century corresponds to the previously mentioned privatization in the metallurgical industry. After 2009, fluctuations can be seen only within the production frontier. Thus, it can be stated that the crisis affected the economy as a whole, but the development of technical efficiency stabilized after the crisis.

\section{DISCUSSION}

According to the results, it can be stated that the metallurgical industry underwent significant development during the period under review (especially in the Czech Republic). Unfortunately, no studies of a similar type are currently available for this sector. Studies such as Li, Chiu and Lin (2019) or Wang, Wan and Yang (2019) focus only on specific companies operating in the coal industry in China. Some studies evaluating the metallurgical industry in one of the countries in Europe can be found - for example, a study by Ioana, Semenescu and Costoiu (2017) or Roubalová, Hampel and Viskotová (2018), where only ratios were used to evaluate efficiency. It is therefore not an evaluation of efficiency in its full sense, but only an expression of a unit's productivity. Although it is possible to sort the resulting productivity values and make a certain comparison, the links between units are not taken into account in the calculation of the indicator itself. However, Ioana, Semenescu and Costoiu (2017) also emphasize that processes in the metallurgical industry are improving and article of Roubalová, Hampel and Viskotová (2018) showed that technological progress is taking place in the metallurgical industry. 
For the purpose of evaluating changes in efficiency, three types of SFA panel models with different settings were selected. Although all three of these types of models do not agree on the absolute level of country efficiency, the development is the same for all types of models. In particular, TD models showed lower values of technical efficiency. At this point, it is possible to refer to the work of Sun et al. (2017), where TD models also achieved significantly lower efficiency values compared to models with effects. TD models with their settings tend to overestimate the inefficiency, which therefore reduces the efficiency of the unit.

The results of individual types of SFA models differ in terms of countries rank derived from the average efficiency (see Tab. IV). The rank visibly differs for countries such as Germany and Spain. For example, Germany stands at the top in terms of TD models, but in terms of "true" models Germany appears among the countries with below-average efficiency. In this respect, the differences between the TD models and the "true" models became apparent. Here it is possible to refer to the results of Staňková and Hampel (2020), where it was demonstrated on the basis of correlation coefficients that the TD models estimated by them usually had a weak correlation with the results of "true" models.

The results of SFA models were contrasted with the results of the DEA method (respectively MI). It can be stated that the development of efficiency according to the average values for individual groups of SFA models is in accordance with the results of MI. The models can be considered realistic also from the point of view that fluctuations in efficiency fully correspond to economic changes (as was demonstrated in detail using the example of the Czech Republic). Here, Silva et al.'s assumption that both approaches lead to similar results when using aggregated data was confirmed.

\section{CONCLUSION}

It can be stated that since 1995 the efficiency of the metallurgical industry has changed. However, this change is individual to specific countries. On average for all chosen EU countries, the efficiency values in 2015 are two percentage points higher than those in 1995. Companies in the Czech Republic had the greatest impact on this increase in efficiency. At the beginning of the period under review, the Czech Republic lagged significantly behind other EU countries in terms of efficiency. At the end of the period under review, however, its results are comparable with the others.

With regard to the aim of the article, the efficiency was estimated based on three types of SFA models with different settings. The efficiency development (in average values) is the same in all model types. The credibility of the SFA panel models was verified by the competitive non-parametric method.

\section{Acknowledgements}

This article was supported by the grant No. PEF/TP/2020002 of the Grant Agency IGA PEF MENDELU.

\section{REFERENCES}

BATTESE, G. E. and COELLI, T. 1988. Prediction of firm-level technical efficiencies with a generalized frontier production function and panel data. Journal of Econometrics, 38(3): 387-399.

BATTESE, G. E. and COELLI, T. 1995. A Model for Technical Inefficiency Effects in a Stochastic Frontier Production Function for Panel Data. Empirical Economics, 20(2): 325-332.

BELOTTI, F., DAIDONE, S., ILARDI, G. and ATELLA, V. 2013. Stochastic frontier analysis using Stata. Stata Journal, 13(4): 718-758.

COOPER, W. W., SEIFORD M. L. and TONE, K. 2007. Data envelopment analysis: a comprehensive text with models, applications, references and DEA-solver software. $2^{\text {nd }}$ Edition. New York: Springer.

EUROPEEAN COMMISSION. 2004. Metallurgy made in and for Europe. $1^{\text {st }}$ Edition. Luxembourg: Publications Office of the European Union.

GREENE, W. H. 2005. Reconsidering heterogeneity in panel data estimators of the stochastic frontier model. Journal of Econometrics, 126: 269-303.

HOSSEINZADEH, A., SMYTH, R., VALADKHANI, A. and LE, V. 2016. Analyzing the efficiency performance of major Australian mining companies using bootstrap data envelopment analysis. Economic Modelling, 57: 26-35.

CHAROENRAT, T. and HARVIE, C. 2014. The efficiency of SMEs in Thai manufacturing: a stochastic frontier analysis. Economic Modelling, 43: 372-393.

IOANA, A., SEMENESCU, A. and COSTOIU, C. 2017. Research and Devolopment about Metallurgical Industry of Romania. In: MAAD, S. (Ed.). Research and Development Evolving Trends and Practices Towards Human, Institutional and Economic Sectors Growth. IntechOpen. 
JONDROW, J., LOVELL, C. A. K., MATEROV, I. S. and SCHMIDT, P. 1982. On the estimation of technical inefficiency in the stochastic frontier production function model. Journal of Econometrics, 19(2-3): 233-238.

KNÍŽEK, M. 2018. Příběh Vítkovických železáren odráží historii českého hutního průmyslu. Po rozvoji ve 20. století přišel výrazný útlum na přelomu milénia. Hospodářské noviny. [Online]. Available at: https://archiv.ihned.cz/c1-66299750-historie-vitkovickych-zelezaren [Accessed: 2020, August 1].

KUMBHAKAR, S. C., WANG, H. and HORNCASTLE, A. P. 2015. A Practitioner's Guide to Stochastic Frontier Analysis Using Stata. $1^{\text {st }}$ Edition. Cambridge: Cambridge University Press.

LI, Y., CHIU, Y. and TAY-YU, L. 2019. Coal production efficiency and land destruction in China's coal mining industry. Resources Policy, 63: 101449.

ROUBALOVÁ, L., HAMPEL, D. and VISKOTOVÁ, L. 2018. Technological Progress at the Sectoral Level: the Sato Production Function Approach. In: Mathematical Methods in Economics 2018: Conference Proceedings. MatfyzPress: Praha, pp. 470-475.

SILVA, T. C., TABAK, B. M., CAJUEIRO, D. O. and DIAS, M. V. B. 2016. A comparison of DEA and SFA using micro- and macro-level perspectives: Efficiency of Chinese local banks. Physica A: Statistical Mechanics and its Applications, 469: 216-223.

STAŇKOVÁ, M. and HAMPEL, D. 2018. Efficiency Comparison in the Development of Building Projects Sector. In: Mathematical Methods in Economics 2018: Conference Proceedings. MatfyzPress: Praha, pp. 503-508.

STAŇKOVÁ, M. and HAMPEL, D. 2019. Efficiency of the Building Project Sector in the Czech Republic - Stochastic Frontier Analysis Approach. In: International Conference of Numerical Analysis and Applied Mathematics (ICNAAM 2018). Melville: American Institute of Physics (AIP).

STANKKOVÁ, M. and HAMPEL, D. 2020. On the Influence of Model Setting on Stochastic Frontier Analysis. Mathematical Methods in the Applied Sciences, 2020: 6730.

SUN, C., LUO, Y., HUANG, Y. and OUYANG, X. 2017. A comparative study on the production efficiencies of China's oil companies: A true fixed effect model considering the unobserved heterogeneity. Journal of Cleaner Production, 154: 341-352.

THANASSOULIS, E. 2013. Introduction to the Theory and Application of Data Envelopment Analysis: A Foundation Text with Integrated Software. $2^{\text {nd }}$ Edition. New York: Springer.

WANG, D., KAIDI, W. and JINGYUAN, Y. 2019. Measurement and evolution of eco-efficiency of coal industry ecosystem in China. Journal of Cleaner Production, 209: 803-818.

WU, Y., JINGRONG, S., KE, L. and CHUANWANG, S. 2019. Comparative study on power efficiency of China's provincial steel industry and its influencing factors. Energy, 175: 1009-1020.

YANG, W., SHAO, Y., QIAO, H. and SHOUYANG, W. 2014. An Empirical Analysis on Regional Technical Efficiency of Chinese Steel Sector based on Network DEA Method. Procedia Computer Science, 31: 615-624.

Contact information

Michaela Staňková: michaela.stankova@mendelu.cz 